Prof. dr Radovan Grandić, red. prof. u penziji Maja Bosanac

Univerzitet u Novom Sadu, Filozofski fakultet doi: 10.19090/zop.2018.27.7-27

UDC: $378.4 .014 .3(497.11)$

Pregledni rad

\title{
RAZVOJ TREĆE MISIJE UNIVERZITETA U SRBIJI*
}

\begin{abstract}
Apstrakt: Univerziteti su još od svog osnivanja u srednjem veku bili neodvojivi od društva u kojem deluju; međutim, u različitim istorijskim periodima prioritet se davao različitim misijama. Pored nastave $\mathrm{i}$ istraživanja kao osnovnih univerzitetskih misija, pod trećom misijom univerziteta podrazumeva se odnos univerziteta i zajednice. U radu se opisuju društvene promene koje dovode do otvaranja univerziteta prema spoljašnjem okruženju. Polazeći od stanovišta prema kojem se treća misija univerziteta sastoji od dve dimenzije društvene, civilne i ekonomske, koje treba da budu ravnopravne - kao cilj rada postavlja se sagledavanje perspektive razvoja treće misije univerziteta u Srbiji, sa posebnim akcentom na društvenu i civilnu dimenziju. Cilj je operacionalizovan kroz dva zadatka: prvi se odnosi na definisanje treće misije i analizu internacionalnog projekta Institucionalni okvir za razvoj treće misije univerziteta u Srbiji koji se trenutno realizuje; drugi zadatak jeste komparacija dve paradigme kroz koje može da se realizuje treća misija univerziteta, služenje zajednici (community service), nasuprot paradigmi zalaganja u zajednici (community engagement). Kao zaključak rada ističe se kako postoje osnove za aktuelizaciju proučavanja treće misije univerziteta u Srbiji, ali se primećuje veća usmerenost ka komercijalnoj i ekonomskoj u odnosu na društvenu i civilnu dimenziju.
\end{abstract}

Ključne reči: univerzitet, misije univerziteta, treća misija univerziteta.

\section{UVOD}

Visoko obrazovanje prolazi kroz period značajnih transformacija koje su uslovljene brojnim društvenim promenama. Klark Ker (Kerr, 2001) ističe stav kako su univerziteti započeli od jedinstvene zajednice univerzitetskih nastavnika i studenata (lat. universitas magistrorum et scolarium), međutim, danas je situacija drugačija i univerziteti moraju da zadovolje mnoge

\footnotetext{
${ }^{*}$ Rad je nastao u okviru projekta Pedagoški pluralizam kao osnova strategije obrazovanja (179036) koji finansira Ministarstvo prosvete, nauke i tehnološkog razvoja.

Maja Bosanac, bosanac.maja4@hotmail.co.uk
} 
zainteresovane strane. Ker (Kerr, 2001) čak govori i o ideji zamene termina univerzitet (university) terminom multiverzitet (multiversity). Iako ova ideja trpi i kritike, Ker (Kerr, 2001) naglašava kako je ona realnost zasnovana u istoriji, da je više imperativ nego izbor među alternativama.

Pored nastave i istraživanja, kao osnovnih akademskih delatnosti, posebno u periodu tranzicije, značajna je i treća misija univerziteta koja se ogleda u učešću univerziteta u ekonomskom razvoju i izgradnji civilnog društva i demokratskih vrednosti (Spasojević, Kleut i Branković, 2012). Ćulum i Ledić $(2011,17)$ postavljaju specifična istraživačka pitanja koja se odnose na treću misiju univerziteta: proučavanje svrhe univerziteta; sukob paradigmi visokog obrazovanja kao javnog i privatnog dobra; dinamika odnosa univerziteta $\mathrm{i}$ pojedinih učesnika u zajednici, posebno tržišta i industrije; uticaj obrazovnih politika na razvoj $\mathrm{i}$ promene $\mathrm{u}$ visokom obrazovanju; aktivnosti i mehanizmi koje univerziteti koriste u nastojanju da odgovore na raznovrsne potrebe svojih učesnika; podsticaji i inhibitori saradnje univerziteta i zajednice; položaj nastave i istraživanja u kontekstu obrazovanja društveno odgovornih i aktivnih građana, te doprinos i razvoj zajednice; uloga univerzitetskih nastavnika u promociji javne dimenzije delovanja, odnosno zalaganja u zajednici.

Kada je u pitanju predviđanje budućnosti treće misije univerziteta, Roper i Hirt (Roper \& Hirth, 2005) postavljaju nekoliko pitanja. Koliko je jaka trenutna potreba demokratije za ulaganja u partnerstvo i ekonomski razvoj sa institucijama visokog obrazovanja? Da li postoje šanse da se treća misija podigne u hijerarhiji visokog obrazovanja? Kakav će biti uticaj stalnog smanjenja državne pomoći na treću misiju? S obzirom da uključena partnerstva podstiču preduzetništvo i ekonomski razvoj, koliko je verovatno 
da u narednih nekoliko decenija treća misija dobije na značaju i možda postane primarni fokus u nekim javnim institucijama?

Klark Ker (Kerr, 2001), naime, ističe kako su univerziteti - primarno koncipirani kao jedinstvena zajednica univerzitetskih nastavnika i studenata danas u obavezi da zadovolje mnoge zainteresovane strane. Dodatno, pojavljuju se sintagme kao što je univerzitet koji je „opterećen misijama“ (Jongobled, Enders \& Salerno 2008), „pod stresom“ (Olsen \& Maassen, 2007) i slično. Imajući navedeno $u$ vidu, a usled promena u načinu finansiranja, kao i zbog pojave sve većeg broj učesnika i zainteresovanih strana, nameće se potreba za proučavanjem treće misije univerziteta, njenih mogućnosti, ali isto tako i izazova. U izveštaju Međunarodne komisije o obrazovanju za 21. vek, koji podnosi Žak Delor (J. Delors) pod naslovom Obrazovanje - skrivena riznica, ističe se niz suprotnosti koje će u budućnosti da sve više dođu do izražaja: (1) suprotnost između globalnog i lokalnog, (2) suprotnost između univerzalnog i individualnog, (3) suprotnost između tradicije i savremenih tendencija, (4) suprotnost između dugoročnih i kratkoročnih okolnosti, (5) suprotnost između potrebe za takmičenjem i težnje ka jednakim mogućnostima, (6) suprotnost između ogromnog razvoja znanja i čovekovih mogućnosti da ga usvoji, (7) suprotnost između duhovnog i materijalnog sveta (Delor, 1996).

Rasprave o razvoju treće misije univerziteta ne mogu da budu potpune bez predstavljanja razvoja univerziteta i njegovih misija počev od nastanka univerziteta u srednjem veku i misije poučavanja, zatim Humboltovog istraživačkog univerziteta, sve do pojave globalizacije i misije internacionalizacije. Jedan od sveobuhvatnijih pristupa istorijskom razvoju univerziteta i njegovih misija jeste periodizacija Džona Skota (Scott, 2006), 
koji ulogu univerziteta posmatra kroz tri osnovna perioda: (1) period pre formiranja nacionalnih država, kada prevladava misija poučavanja i istraživanja, (2) period izgradnje nacionalnih država, u kojem se pojavljuju misija službe državi, misija demokratizacije i misija javne službe zajednici, (3) period globalizacije koji sa sobom donosi najviše kontroverzi, a kao najistaknutija postaje misije internacionalizacije.

U Strategiji razvoja obrazovanja u Republici Srbiji do 2020. ističe se sledeće: do sada su bili retki pokušaji da se razvoj sistema obrazovanja razume sa stanovišta njegove misije i funkcija prema spoljnjem svetu u kojem funkcioniše i radi kojeg postoji; sistem obrazovanja treba posmatrati u celini; to posmatranje i projektovanje njegovog razvoja treba da bude izvedeno uz stvarno učešće celokupne javnosti, posebno one koje se obrazovanje najviše tiče; vode se javne rasprave o obrazovanju među stručnjacima različitih profila obrazovanja; te rasprave treba da budu kritički stvaralačke i argumentovane; sistem obrazovanja treba doslovno da se otvori prema zajednici u kojoj postoji; njime niko ne sme da manipuliše i koristi u svrhe zadovoljenja interesa određenih grupa; trebalo bi izgraditi populaciju moderno obrazovanu, kreativnu, motivisanu za učenje i osposobljenu za primenu stečenog znanja. Uz to, trebalo bi naglasiti i činjenicu da je u savremenim okolnostima u Srbiji sistem obrazovanja zatvoren u sebe, odvojen od svog okruženja, oblikovan prema komercijalnim interesima, izložen partijskim uticajima, kratkoročno doterivan uglavnom sa ciljem da se svi interesi zadovolje bez obzira na dugoročne posledice takvog načina rešavanja problema. Zastupajući stanovište po kojem misije i funkcije univerzieta, kao i odnos univerziteta prema spoljašnjem sistemu, sve više dobijaju na značaju - u radu se pažnja usmerava na treću misiju univerziteta. 


\section{KA DEFINISANJU TREĆE MISIJE UNIVERZITETA}

Na osnovu pregleda literature, može se konstatovati da je pitanje treće misije univerziteta kontroverzna tema iz više razloga. U tom smislu u literturi ne samo da se uočava izuzetno razuđen dijapazon pojmovnog određenja treće misije univerziteta, nego i naglašena terminološka neujednačenost koja dodatno otežava istraživanje.

Autorke Ćulum i Ledić (2011:18) treću misiju shvataju kao odnos između visokog obrazovanja i društva izvan prve (nastava) i druge (istraživanje) misije; „nova“, dvostruka uloga univerziteta: kao nosioca pozitivnih promena koje doprinose društvenom razvoju i preduzetnika koji doprinose ekonomskom razvoju. Goranson i sar. (Göransson, Maharajh \& Schmoch, 2009 ) uočavaju, takođe, da postoje značajne varijacije između zemalja i različitih konteksta u pogledu toga kakve funkcije treba da se uključe u treću misiju univerziteta. One sežu od fokusa na transferu tehnologija od univerziteta prema preduzećima (u Nemačkoj), do šireg latinoameričkog koncepta proširenja uloge univerziteta da služi potrebama zajednice. Još jedno od pitanja koje se postavlja je da li je treća misija univerziteta nova ili ne? Nedeva (Nedeva, 2008, prema: Mugabi 2014) navodi da, ako posmatramo treću misiju kao skup aktivnosti, to nije nova funkcija jer je priča o univerzitetu nerazdvojiva od njegove odgovornosti prema društvu i ekonomiji, dok, s druge strane, ono što je novo je dubina i obim interakcije između zajednica i univerziteta (Benneworth, Conway, Charles, Humphrey \& Younger, 2009). Ako se,dakle, postavi pitanje da li je treća misija univerziteta nova ili ne, sasvim je izvesno da jedinstvenog odgovora nema budući da se stavovi istraživača razlikuju (Laredo, 2007, prema: Mugabi 2014). Na slična razilaženja u stavovima nailazi se kad se 
postavi pitanje treba li misija univerziteta da bude povezana sa nastavom i istraživanjem ili u potpunosti izolovana od njih (Greenbank, 2006, Karlsson, 2007, Barnett, 2005).

U literaturi se (Mugabi 2014) treća misija univerziteta konceptualizuje na više načina.

1. Razmatra se kao promena načina proizvodnje znanja (Gibbons et al., 1994), pri čemu se u okviru ove interpretacije uočavaju dva modela. Model 1 karakteriše disciplinarnost, u njemu prevladava naučno otkriće sa strogom unutrašnjom hijerarhijom među disciplinama, usmerenost na osnovna istraživanja, pri čemu je produkcija znanja primarno kognitivna. Suprotno, model 2 je transdisciplinaran, usmeren na primenjena istraživanja unutar društvenog i ekonomskog konteksta. Oba koncepta su značajna i korisna prilikom analize prirode odnosa između univerziteta i društva,

2. Treća misija univerziteta konceptualizuje se u literturi i kao model trostruke spirale (Triple Helix Model) koji se zasniva na privatno javnim partnerstvima, saradnji univerziteta, privrede i države (Etzkowitz \& Leydesdorff, 1997),

3. Prilikom promene društvenog ugovora između države i univerziteta (Duderstadt, 1999; Vavakova, 1998) ne postavlja se pitanje da li će visoko obrazovanje biti transformisano, već kako i od strane koga.

4. Pojedini autori treću misiju definišu kao drugu akademsku revoluciju i pojavu preduzetničkog univerziteta (Duderstadt, 1999; Vavakova, 1998),

5. Ona se može posmatrati i iz perspektive prirodne uloge evolucije nastave koja podrazumeva proširenje ciljne populacije i 
diversifikaciju kurikuluma radi uspostavljanja netradiconalnog odnosa sa industrijom i nacionalnim i internacionalnim institucijama $\mathrm{i}$ zbog integracije razvoja istraživačkih rezultata (Montesinos, Carot, Martinez \& Mora, 2008).

6. Konačno, treća misija univerziteta izjednačava se sa pojmom preduzetnički univerzitet (Vorley \& Nelles, 2008). Preduzetnički model postaje legitiman organizacioni princip za koji se smatra da je u stanju da omogući institucijama visokog obrazovanja da se nose sa izazovima u novom okruženju (Vaira, 2004). U raspravama u sektoru visokog obrazovanja priznaje se trend ,preduzetničkog univerziteta“, što je rezultiralo pluralizmom terminoloških određenja usled čega Arnovič (Aronowitz, 2000) koristi termin fabrika znanja (knowledge factory), Klark (Clark, 1998) govori o preduzetničkom univerzitetu (entrepreneurial university), Sloter i Lesli (Slaughter \& Lesly, 1997) uvode koncept akademskog kapitalizma (academic capitalism), a Gumport (Gumport, 2000) upotrebljava koncept industrije visokog obrazovanja (concept of higher education industry).

Sve ovo utiče na raslojavanje akademskih predmeta, znanja i disciplina i na uvećanu upotrebnu vrednost i razmenu vrednosti određenog znanja u širem društvu, potom na nastanak akademskog konzumerizma koji obnavlja veze između institucija visokog obrazovanja, njihovih klijenata i različitih zainteresovanih strana (Etzkowitz and Leysdorff 1997; Gumport 2000; Rhoades and Slaughter 1997, prema: Vaira, 2004).

U kontekstu isticanja konkurentnosti i naglašenije povezanosti univerziteta i ekonomije (EC, 2005) zastupljenija je terminologija koja se odnosi na transfer tehnologija i inovacije (u engleskom govornom području 
neki od češće upotrebljavanih temina su sledeći: technology transfer, entrepreneurial university, university third leg) i slično.

$\mathrm{Na}$ konferencijama koje su održane nakon 2005. godine navode se specifični ciljevi koji se posebno odnose na usaglašavanje visokog obrazovanja sa potrebama tržišta rada, podsticanje saradnje sa različitim institucijama i istraživačkim delatnostima, razvijanje evropskog okvira kvalifikacija, formulisanje ishoda učenja i razvijanje kompetencija potrebnih društvu znanja (Lungulov, 2015:19).

Grupa istraživača predvođenih uglavnom severnoameričkim autorima (Checkoway, 2001; Ostrander, 2004; Harkavy, 2006) i kritičarima ističu važnost društvenog segmenta treće misije, u literturi dominantno nazvanog civilna misija univerziteta (university civic mission), i zauzimaju stav prema kojem je civilna misija jedna i jedina treća misija univerziteta. Kritika koju upućuje Ostrander (Ostrander 2004) odnosi se na činjenicu da civilno zalaganje ne sme da bude posmatrano isključivo kroz prizmu pozitivnog uticaja na moralni razvoj studenata jer će u tom slučaju ono biti shvatano samo kao marginalizovana delatnost. Umesto toga, autorka ističe značaj podsticanja integracije civilne misije u osnovne akademske delatnosti, pri čemu je izuzetno važno da se civilno zalaganje zasniva na otkrivanju i sticanju novog znanja.

U radu zastupamo stanovište da treća misija univerziteta (university third mission) podrazumeva i društvenu i ekonomsku dimenziju (Schoel, 2006) i da one treba da budu podjednako značajne. 


\section{INSTITUCIONALNI OKVIR ZA RAZVOJ TREĆE MISIJE UNIVERZITETA U SRBIJI}

$\mathrm{S}$ obzirom da je proučavanje treće misije univerziteta u Republici Srbiji još uvek u začecima, sama činjenica da je u toku realizacija međunarodnog projekta Institucionalni okvir za razvoj treće misije univerziteta u Srbiji (realizacija je započela 15. oktobra 2015. i trajaće do oktobra 2018. godine) govori u prilog aktueliazaciji ove teme.

Proučavanje treće misije univerziteta na ovom projektu zasniva se na tri osnovna stuba razvoja (Tabela 1): (1) transfer tehnologija i inovacije, (2) kontinuirano učenje i (3) društveno odgovorno ponašanje univerziteta. Pretpostavlja se da će proučavanje treće misije univerziteta u Srbiji u budućnosti poprimiti još veći značaj, na šta upućuje i činjenica da su u okviru projekta formirana i stručna tela sa incijativama za izmene i dopune ili sačinjavanje novog zakona koji se odnose na treću misiju univerziteta (detaljnije: D.1.3 Izveštaj o postojećim strategijama i zakonima Republike Srbije koji se odnose na dimenzije treće misije).

Tabela 1: Lista mogućih indikatora za merenje progresa ili uspeha društvene uključenosti

\begin{tabular}{lll}
\hline Broj & Tip/vrsta & Indikator \\
\hline 1 & Transfer & Broj projekata koji imaju benefite za širu \\
& tehnologije i & zajednicu \\
inovacija & Broj ljudi na koje su uticali projekti \\
& Broj ugovora univerziteta/fakulteta sa industrijom \\
& Broj ugovora sa javnim telima \\
& Broj univerzitetskih/fakultetskih \\
& centara/labaratorija/izvora prezentovanih široj \\
& zajednici \\
& Broj ljudi koji su koristili \\
& univerzitetske/fakultetske prostore \\
& Broj otvorenih kampanja \\
\hline
\end{tabular}


Broj studenata/istraživača uključenih u otvorene kampanje

Broj učesnika na istraživačkim noćima

Broj učesnika na danima otvorenih vrata

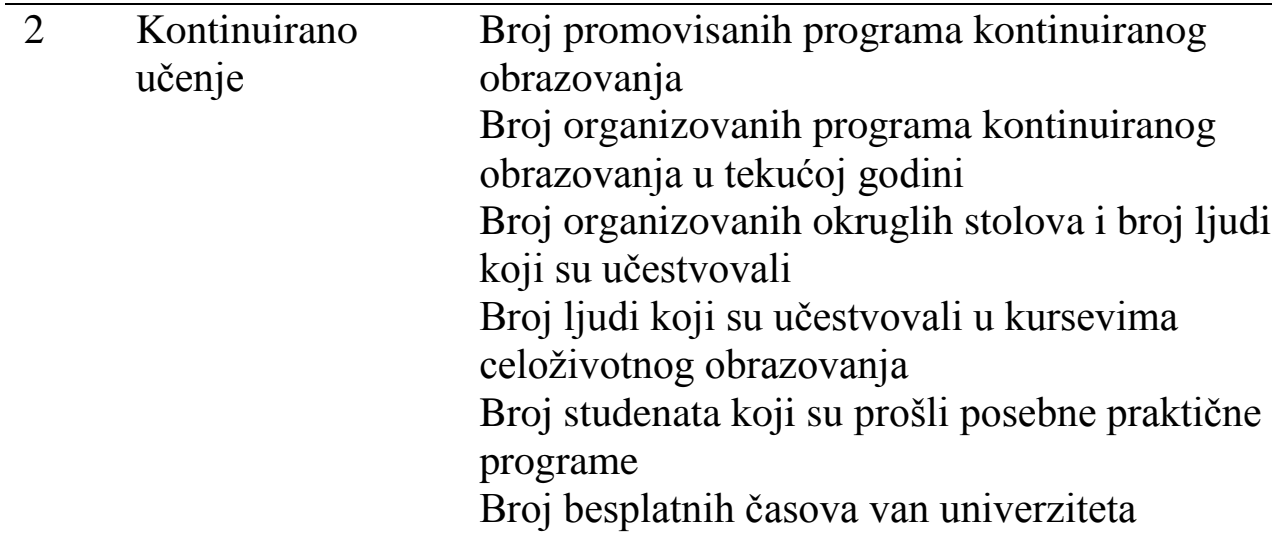

\begin{tabular}{lll}
\hline 3 & $\begin{array}{l}\text { Društveno } \\
\text { odgovorno } \\
\text { ponašanje }\end{array}$ & Broj ljudi van univerziteta koji su koristili \\
& prostor/usluge biblioteke \\
& Broj učesnika van univerziteta koji su koristili \\
& prostorije za organizovanje konferencija, \\
& sastanaka, događaja i slično \\
& Broj univerzitetskih nastavnika/studenata koji su \\
& volontirali za dobrobit šire zajednice \\
& Broj organizovanih takmičenja \\
& Broj učesnika \\
& Broj javnih debata o važnim društvenim pitanjima \\
\hline
\end{tabular}

Izvor: Individualni plan društvene uključenosti za Novosadski univerzitet (2017)

I u ovom se projektu mogu uočiti veća usmerenost ka ekonomskoj dimenziji treće misije univerziteta, kao i kvantitativni pokazatelji realizovanja ove misije u odnosu na društvenu i civilnu, koja se najvećim delom svodi na aktivnosti u kojima univerzitet pruža usluge zajednici. Tendencija ka dominantnijoj ekonomskoj dimenziji nije iznenađujuća imajući, pre svega, u vidu ekonomsku isplativost i sve rašireniju pojavu saradnje između 
univerziteta, industrije i privrede. Konrad Pol Lisman (Liessmann, 2008), jedan od najoštrijih kritičara implementacije bolonjske reforme univerziteta, ističe da - ukoliko se znanje posmatra samo u okvirima iskoristivosti - onda to nije pitanje znanja, već situacije u koju se dospeva. Jovanović - Kranjec (2013) ukazuje na to kako ekonomizacija visokog obrazovanja postavlja na margine osnove humanističkih vrednosti obrazovanja.

Ričard Hoftšater (Richard Hofstadter) je uočio opasnosti koje korporativne vrednosti stavljaju pred obrazovanje navodeći kako se najbolji razlog za podržavanje institucija visokog obrazovanja ne pronalazi u službi koju ove institucije mogu da obavljaju, već u vrednostima koje zastupaju. Vrednosti pravde, slobode, jednakosti i prava građana kao jednakih i slobodnih ljudskih bića - od središnje su važnosti za ulogu visokog obrazovanja u obrazovanju studenata o upravljanju, socijalnom građanstvu i demokratskoj javnoj sferi (Aronowitz i Giroux prema: Jovanović-Kranjec 2013, 93).

Izneta zapažanja o odnosu društene i civilne i ekonomske dimenzije treće misije univerziteta posebno su značajna za našu akademsku zajednicu u fazi u kojoj rasprave o trećoj misiji univerziteta tek dobijaju na značaju. Međutim, proučavanje odnosa univerziteta i društva može da se prati još od donošenja Opšteg zakona o univerzitetu 1954. godine, u kojem se ističe značaj bliže saradnje univerziteta sa društvom i privredom, kao i pitanjem kontrole društva nad radom univerziteta (prema: Bondžić, 2010). 


\section{PARADIGMA SLUŽENJA ZAJEDNICI NASUPROT PARADIGME ZALAGANJA U ZAJEDNICI}

Činjenica da su univerziteti još od svog osnivanja u srednjem veku bili nedovojivi od društva u kojem deluju ukazuje na značaj proučavanja odnosa univerziteta i njegovog spoljašnjeg okruženja. U današnje vreme $u$ kojem dolazi do brojnih promena uslovljenih, pre svega, procesom globalizacije, masovnim visokoškolskim obrazovanjem, kao i promenama $\mathrm{u}$ načinu finansiranja - odnos univerziteta i spoljašnjeg okruženja postaje sve značajniji. Pazvoj obrazovanja u današnje vreme više nije toliko podstican svojom unutrašnjom dinamikom razvoja, kao što je to bio slučaj u prošlosti, već je postao puno osetljiviji prema spoljašnjim pritiscima (Milutinović, 2008). Uz to, konstantni zahtevi za unapređenjem univerziteta dolaze iz različitih sektora društva. Jedna od kritika koja je upućena visokom obrazovanju jeste da institucije treba da više doprinose svojim zajednicama (Lombardi, Craig, Capaldi, Gater \& Mendonça, 2001).

U cilju isticanja značajnih razlika između dve paradigme treće misije univerziteta, u Tabeli 2 predstavljene su osnovne razlike između paradigme služenja zajednici (community service) i paradigme zalaganja u zajednici (communitu engagement). Adams i saradnici (2005) ističu značajne razlike između dve paradigme. U okviru prve paradigme ističe se služba zajednici (community service) u kojoj su aktivnosti treće misije dodane uz nastavu i istraživanje pri čemu je univerzitet stručnjak u zajednici. Kod ove paradigme dominira filantropski model - univerzitet pruža usluge zajednici. Prema postavkama druge paradigme, tj. paradigme zalaganja u zajednici (community engagement), aktivnosti treće misije integrišu u nastavu i istraživanje, a znanje i veštine koje poseduje zajednica uočene su i vrednovane na univerzitetu kao relevantan izvor znanja i učenja. Pored toga, u drugoj 
paradigmi preovladava partnerski model - univerzitet i zajednica sarađuju radi postizanja zajedničkih ciljeva od kojih obe strane imaju koristi.

Iako se ne negira kompleksnost i složenost ovog pristupa, u radu se zastupaju načela paradigme koja se odnosi na zalaganje $\mathrm{u}$ zajednici (community engagement). Osnovna kritika koju je Fleksner (Flexner, 1994) upućivao, pre svega američkim univerzitetima, bila je činjenica da obrazovanje nisu cenili kao iskustvo već kao alat, te da je služenje zajednici bilo svedeno na pokušaj univerziteta da sebe učine korisnima kako bi se opravdali u javnosti, kao i preveliko isticanje socijalnih aktivnosti u odnosu na aktivnosti intelektualnog truda.

Tabela 2: Dve paradigme treće misije kao službe zajednici i treća misija kao zalaganje u zajednici

Paradigma službe zajednici Community service

Aktivnosti treće misije dodane uz nastavu i istraživanje

Univerzitet je stručnjak u zajednici
Paradigma zalaganja u zajednici Community engagement

Aktivnosti treće misije integrisane $u$ nastavu i istraživanje

Znanje i veštine koje poseduje zajednica uočene su i vrednovane na univezitetu kao relevantan izvor znanja i učenja

Filantropski model - univerzitet daje, pruža usluge zajednici
Partnerski model - univerzitet $\mathrm{i}$ zajednica sarađuju u cilju postizanja zajedničkih ciljeva od kojih obe strane imaju korist

Izvor: Adams i sar. (2005)

Polazeći od stanovišta da realizaciji treće misije univerziteta treba da se pristupi iz ugla paradigme zalaganja u zajednici, neophodno je i da se istakne kompleksnost ovog pristupa. Jedno od značajnijih pitanja jeste: ko su 
adekvatni partneri univerziteta prilikom postizanja zajedničkih ciljeva od kojih obe strane treba da imaju korist? Sledeće značajno pitanje jeste: koliko su uopšte predstavnici akademske i lokalne zajednice zainteresovani za ovakav vid saradnje? Dakle, elaboracijom predstavljenih istraživanja i stavova o trećoj misiji univerziteta - bez obzira na stav treba li univerziteti da se otvaraju prema spoljašnjoj zajednici i budu partneri prilikom realizovanja zajedničkih ciljeva - upućenost u tematiku treće misije univerzitita veoma je značaja za sve predstavnike akademske zajednice a u budućnosti pitanja koja se odnose na treću misiju univerziteta mogu da poprime još šire razmere.

U kontekstu nedovoljne istraženosti i nedovoljnog broja podataka iz prakse o načinima realizacije i sprovođenja treće misije na našim univerzitetima, valja skrenuti pažnju na činjenicu da proučavanje treće misije univerziteta u Republici Srbiji trenutno može da rezultira većim brojem pitanja i dilema nego konkretnih odgovora. Način na koji je izvršena implementacija i institucionalizacija treće misije univerziteta na univerzitetima $\mathrm{u}$ drugim zemljama pruža značajne i korisne podatke koji zasigurno mogu da posluže kao polazna osnova za dalji istraživački rad iako ne mogu $u$ potpunosti da budu direktno primenjivi $u$ našim akademskim zajednicama. U cilju boljeg razumevanja savremenog odnosa univerziteta i zajednice, neophodno je da se analitički pristupi i razvoju univerzitetskog obrazovanja posmatrajući istorijski kontekst. Proučavanje razvoja nauke i njenog odnosa sa privredom i društvom iz posleratnog perioda, što je bilo uslovljeno posledicama ratnih i revolucionarnih zbivanja (Bondžić, 2008), može da predstavlja dobru polaznu osnovu za bolje razumevanje specifičnosti trenutnog odnosa univerziteta sa zajednicom na teritoriji Republike Srbije. 


\section{ZAKLJUČNA RAZMATRANJA}

Savremeni univerziteti suočavaju se sa brojnim izazovima, mnoštvom uloga koje se pred njima nalaze, kao i očekivanjima brojnih i različitih zainteresovanih strana. Pitanje razvoja treće misije univerziteta puno je kontroverzi, počevši od shvatanja da uopšte ne treba da se raspravlja o trećoj misiji, sve do stavova da treća misija treba da bude prva. Međutim, i kada se pridaje značaj trećoj misiji univerziteta, postavlja se pitanje njenog definisanja, zatim odgovora na pitanje kakav odnos univerziteta i društva podrazumeva ova misija, odnosno, koliki značaj se pridaje ekonomskoj u odnosu na društvenu i civilnu dimenziju?

Dosadašnji korpus istraživanja u Republici Srbiji na temu treće misije univerziteta svodi se na nekolicinu radova i preglednih članaka od kojih iako je tema treće misije usko povezana sa društvenim promenama (ekonomske, političke i kulturne tranzicije) koje utiču i na univerzitete, te temama povezanim sa bolonjskim procesom - sveobuhvatnih istraživanja na ovu temu iz pedagoške perspektive još uvek nema.

Postojeći međunarodni projekat Institucionalni okvir za razvoj treće misije univerziteta u Republici Srbiji upućuje na aktuelizovanje ove do sada slabo istražene teme u akademskoj zajednici u Republici Srbiji. Pretpostavlja se da će proučavanje treće misije univerziteta u Srbiji ubuduće poprimiti još veći značaj, na šta upućuje i činjenica da su u okviru projekta formirana stručna tela sa inicijativama za izmene i dopune ili sačinjavanje novog zakona koji se odnose na treću misiju univerziteta, ali je moguće uočiti primat koji se ekonomskoj dimenziji daje u odnosu na civilnu i društvenu a koje bi trebalo da imaju ravnopravan odnos. U okviru debate o politici razvoja i uspostavljanja treće misije na univerzitetima u Srbiji, naglašeno je 
da u cilju dokazivanja relevantnosti visokog obrazovanja za društvo u celini treća misija treba da bude prva misija. Takođe, u Strategijama i Zakonima o visokom obrazovanju moguće je uočiti aspekte koji se odnose na treću misiju univerziteta.

Dakle, analizom trenutne situacije, kao i postojeće literature o trećoj misiji univerziteta dolazi se do zaključka da je ova tema nedovoljno proučena u akademskoj zajednici Republike Srbijie, ali se ipak naziru mogućnosti i prilike za aktuelizaciju ovog važnog pitanja.

\title{
DEVELOPMENT OF THE THIRD MISSION OF UNIVERSITIES IN SERBIA
}

\begin{abstract}
Since their development in the Middle Ages, universities have been inseparable from societies they operated in. However in different historical periods, the primate has been given to different missions. Besides teaching and research as basic missions of universities, the third mission of universities implies the relationship between universities and the society. This paper is dealing with social changes that lead to opening universities towards external environment. Starting from the standpoint that the third mission of universities consists of two dimensions: societal and civic, as well as economic dimension that should be equal, this paper has the objective to consider a development perspective of the third mission of universities in Serbia, with a special accent on societal and civic dimension. This objective has been implemented in two tasks: the first one defines the third mission and analyzes the international project that is currently in process, Institutional framework for development of the third mission of universities in Serbia. The second task consists of comparisons of two paradigms through which the third mission of universities can be realized, as follows: community service contrary to community engagement. As a conclusion, it is stated that there are fundamentals for actualization of studies on the third mission of universities in Serbia. However, there has been noticed a bigger focus on commercial and economic dimension in comparison to societal and civic ones.
\end{abstract}

KEY WORDS: university, missions of university, the third mission of university. 


\section{REFERENCE}

Adams, R., Badenhorst, A., \& Berman, G. (2005). The value of performance indicators supporting a community engagement agenda at RMIT. In 2005 Australian Universities Quality Forum: Engaging communities, Sydney: AUQA Occasional Publications.

Aronowitz, S. (2000). The knowledge factory: Dismantling the corporate university and creating true higher learning. Boston: Beacon Press.

Barnett, R. (2005). Reshaping the university: New relationships between research, scholarship and teaching, UK: McGraw-Hill Education.

Benneworth, P. S., Conway, C., Charles, D., Humphrey, L. \& Younger, P. (2009). Characterising modes of university engagement with wider society: A literature review and survey of best practice. Office of the Pro-Vice-Chancellor (Engagement), Newcastle University.

Bondžić, D. (2008). Prosveta i nauka u Srbiji i Jugoslaviji 1945-1990. Beograd. Istorija 20.og veka, 26 (2), 391-437.

Bondžić, D. (2010). Univerzitet u socijalizmu: visoko školstvo u Srbiji 19501960. Beograd: Institut za savremenu istoriju.

Checkoway, B. (2001). Renewing the civic mission of the American research university. The Journal of Higher Education, 72 (2), 125-147. Special Issue: The social Role of Higher Education.

Clark, B. R. (1998). Creating entrepreneurial universities. Organizational pathways of transformation. New York: Pergamon Press.

Delor, Ž. (1996) Obrazovanje - skrivena riznica (UNESCO: Izveštaj međunarodne komisije o obrazovanju za 21.vek). Beograd: Republika Srbija, Ministarstvo prosvete.

Duderstadt, J. J. (1999). New roles for the 21st-century university. Issues in Science and Technology, 16 (2), 37-44. 
EC, (2005) Communication to the Spring European Council. Working Together for Growth and Jobs. A New Start for the Lisbon Strategy COM (2005) 24, Brussels: European Commission.

Etzkowitz, H., \& Leydesdorff, L. (1997). Universities in the Global Economy: A Triple Helix of academic-industry-government relations. London: Croom Helm.

Flexner (1994). Universities: American, English, German. New Bruswick: Tranaction Publishers

Gibbons, M., Limoges, C., Nowotny, H., Schwartzman, S., Scott, P., Trow, M., (1994). The New Production of Knowledge: The Dynamics of Science and Research in Contemporary Societies. London: Sage.

Göransson, B., Maharajh, R., \& Schmoch, U. (2009). New activities of universities in transfer and extension: Multiple requirements and manifold solutions. Science and Public Policy, 36(2), 157-164.

Greenbank, P. (2006). The academic's role: The need for a re-evaluation? Teaching in Higher Education,11(1),107-112.

Gumport, P. J., \& Sporn, B. (1999). Institutional adaptation: Demands for management reform and university administration. Higher education: Handbook of theory and research, 14, 103-145.

Harkavy, I. (2006). The role of universities in advancing citizenship and social justice in the $21^{\text {st }}$ century. Education, citizenship and social justice, 1 (1), 5-37.

Jongbloed. B., Enders, J., Salerno, C. (2008). Higher educationand its communities: Interconnections, interdependencies and a research agenda. Higher Education, 56(3), 303-324. 
Jovanović-Kranjec, M. (2013). Ekonomizacija visokog obrazovanja u Republici Srbiji. Ekonomski horizonti, 1, (87-96).

Karlsson, J. (2007). Service as collaboration: an integrated process in teaching and research. A response to Greenbank. Teaching in higher education, 12(2), 281-287.

Kerr, C. (2001). The uses of the university. Cambridge, MA: Harvard University Press.

Ledić, J., Ćulum, B., (2011) Sveučilišni nastavnici i civilna misija sveučilišta, Rijeka: Filozofski fakultet u Rijeci

Liessmann K. P. (2008). Teorija neobrazovanosti: Zablude društva znanja. Zagreb: Jesenski i Turk

Lombardi, J. V., Craig, D. D., Capaldi, E. D., Gater, D. S., \& Mendonça, S. L. (2001). Quality engines: The strategic principles for competitive universities in the twenty-first century. The Center Reports, University of Florida, March.

Lungulov, B. (2015) Analiza ishoda učenja kao indikatora kvaliteta visokog obrazovanja. Novi Sad: Filozofski fakultet.

Milutinović, J. (2008) Ciljevi obrazovanja i učenja u svetlu dominantnih teorija vaspitanja 20. veka, Novi Sad: Savez pedagoških društava Vojvodine.

Montesinos, P., Carot, J. M., Martinez, J. M., \& Mora, F. (2008). Third mission ranking for world class universities: Beyond teaching and research. Higher Education in Europe, 33(2/3), 259- 271.

Mugabi, H. (2014). Institutionalisation of the 'third mission' of the university: The case of Makerere University. Tampere: Tampere University Press 
Olsen, J. P., \& Maassen, P.A. (2007). European Debates on the Knowledge Institution: The Modernization of the University at the European Level. Maassen \& J.P.Olsen (Eds.), University Dynamics and European Integration, Dordrecht: Springer 3-22.

Ostrander, S. (2004). Democracy, civic participation, and the university: A comparative study of civic engagement on five universities. Nonprofit and voluntary sector quarterly 33(1),74-93.

Roper, C. D., \& Hirth, M. A. (2005). A History of Change in the Third Mission of Higher Education: The Evolution of One-Way Service to Interactive Engagement. Journal of Higher Education Outreach and Engagement, 10(3), 3-21.

Schoel, A. (2006). Strategic Management of University Research Activities. Methodological Guide - PRIME project, Observatory of the European University.

Scott, J. C. (2006) The mission of the university: medieval to postmodern transformations. The Journal of Higher Education. 77(1), 1-39.

Slaughter, S., \& Leslie, L. L. (1997). Academic capitalism: Politics, policies, and the entrepreneurial university. Baltimore: The Johns Hopkins University Press.

Spasojević, D., Kleut, J., i Branković, J. (2012). Društvene promene, Bolonjski proces i treća misija Univerziteta u Srbiji. TEME, 36(3), 1157-1172.

Strategija razvoja obrazovanja u Srbiji do 2020. godine. Službeni glasnik Republike Srbije - Prosvetni glasnik, br. 107. 2012.

Vaira, M. (2004). Globalization and higher education organizational change: A framework for analysis. Higher education, 48 (4), 483-510. 
Vavakova, B. (1998). The new social contract between governments, universities and society: Has the old one failed?. Minerva, 36(3), 209228.

Vorley, T., \& Nelles, J. (2008). (Re)conceptualising the academy: Institutional development of and beyond the third mission. Higher Education Management and Policy, 20(3), 1-17.

Internet izvori:

Individualni plan društvene uključenosti za novosadski univerzitet (2017): nacrt dokumenta (elektronska verzija) pristupljeno 20.12.2017: http://www.if4tm.kg.ac.rs/pub/download/14900148805773_UNS.pdf 
